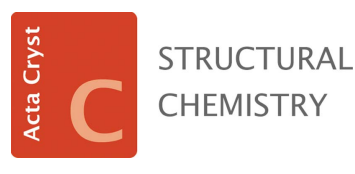

ISSN 2053-2296

Received 28 August 2020

Accepted 15 September 2020

Edited by P. Fanwick, Purdue University, USA

Keywords: cation $-\pi$ interaction; Altretamine; DFT; AIM; NBO; hexamethylmelamine; crystal structure; anticancer drug; computational chemistry.

Supporting information: this article has supporting information at journals.iucr.org/c

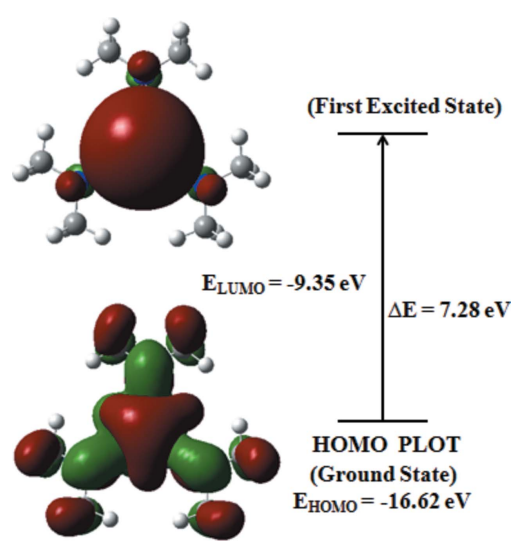

C 2020 International Union of Crystallography

\section{The effect of cation $-\pi$ interactions on the stability and electronic properties of anticancer drug Altretamine: a theoretical study}

\author{
Fahimeh Alirezapour* and Azadeh Khanmohammadi
}

Department of Chemistry, Payame Noor University, PO Box 19395-3697 Tehran, Iran. *Correspondence e-mail: fahimehalirezapour@yahoo.com

The present work utilizes density functional theory (DFT) calculations to study the influence of cation- $\pi$ interactions on the electronic properties of the complexes formed by Altretamine [2,4,6-tris(dimethylamino)-1,3,5-triazine], an anticancer drug, with mono- and divalent $\left(\mathrm{Li}^{+}, \mathrm{Na}^{+}, \mathrm{K}^{+}, \mathrm{Be}^{2+}, \mathrm{Mg}^{2+}\right.$ and $\left.\mathrm{Ca}^{2+}\right)$ metal cations. The structures were optimized with the M06-2X method and the $6-311++\mathrm{G}(\mathrm{d}, \mathrm{p})$ basis set in the gas phase and in solution. The theory of 'Atoms in Molecules' (AIM) was applied to study the nature of the interactions by calculating the electron density $\rho(r)$ and its Laplacian at the bond critical points. The charge-transfer process during complexation was evaluated using natural bond orbital (NBO) analysis. The results of DFT calculations demonstrate that the strongest/weakest interactions belong to $\mathrm{Be}^{2+} / \mathrm{K}^{+}$complexes. There are good correlations between the achieved densities and the amounts of charge transfer with the interaction energies. Finally, the stability and reactivity of the cation $-\pi$ interactions can be determined by quantum chemical computation based on the molecular orbital (MO) theory.

\section{Introduction}

The development of anticancer drugs began four decades ago with the unexpected discovery of the antitumour activity of drugs and their successful use in the behaviour of various cancer cells (Spiegel \& Magistrato, 2006; Deepa et al., 2012). Altretamine (trade name Hexalen) is an anticancer chemotherapeutic drug that works by reducing or stopping the growth of cancer cells (Keldsen et al., 2003). It is known chemically as hexamethylmelamine, which has the empirical formula $\mathrm{C}_{9} \mathrm{H}_{18} \mathrm{~N}_{6}$. Altretamine (ALT) belongs to the group of pharmaceuticals called antineoplastics (Damia \& D'Incalci, 1995). In fact, ALT is a novel synthetic cytotoxic antineoplastic $s$-triazine derivative. This drug is cell cycle nonspecific and works by damaging DNA (Lemke \& Williams, 2008). ALT has been shown to be effective for some ovarian tumours resistant to classical alkylating agents (Keldsen et al., 2003; Chan, 2004). The antitumour activity of ALT is attributed to the $N$-methyl moieties and has the advantage of less toxicity with respect to other drugs (Damia \& D'Incalci, 1995; Malik, 2001). A number of experimental methods based on gas-liquid chromatography with nitrogen-sensitive detection and mass spectrometery (Morimoto et al., 1980; Hulshoff et al., 1980; D'Incalci et al., 1979; Gescher et al., 1980; Klippert et al., 1983) have been applied for the analysis of ALT.

The importance of noncovalent interactions in chemistry cannot be underestimated. These interactions (hydrogen bonding, $\pi$-stacking, cation- $\pi$, etc.) are important in molecular biology, drug design and supramolecular chemistry (Waters, 
2002; Meyer et al., 2003; Hobza, 2008; Hunter et al., 2001; Hunter \& Sanders, 1990; Wheeler et al., 2010). In addition, condensed phase chemistry, biochemistry, surface chemistry, catalysis and polymer science are just a few of the fields of modern chemistry that are significantly defined by noncovalent interaction effects (Müller-Dethlefs \& Hobza, 2000; Černý \& Hobza, 2007; Scherrill, 2009). Cation- $\pi$ interactions, as an ensemble of noncovalent attractions (interaction between a cation and a $\pi$-system), play an important role in many areas ranging from molecular biology to materials design (Ma \& Dougherty, 1997; Kim et al., 2000; Wintjens et al., 2000; Cheng et al., 2006; Ghiassi \& Raissi, 2015). Theoretical (Mecozzi et al., 1996a,b; Gallivan \& Dougherty, 1999; Coletti \& Re, 2006) and experimental (Woodin \& Beauchamp, 1978; Meot-Ner \& Deakyne, 1985; Wouters, 1998; Armentrout \& Rodgers, 2000) studies have revealed that cation- $\pi$ interactions can be very strong, both in the gas phase and in aqueous media. It has been shown that the foremost contributions to the cation $-\pi$ interactions are electrostatic and polarization; they include charge-quadrupole and chargeinduced dipole (Dougherty, 1996; Mecozzi et al., 1996a,b; Archambault et al., 2009). The strength of the electrostatic term depends on the value of the quadrupole moment and the polarization component correlates well with the molecular polarizability values of the aromatic units. In fact, the electronic polarizability is one of the factors that affects the magnitude of the electric field produced by the cation (Caldwell \& Kollman, 1995; Cubero et al., 1998; Tsuzuki et al., 2001; Soteras et al., 2008).

In recent years, the investigation of Altretamine has been considered in various contexts. For instance, in a 2019 study, Khaleghian \& Azarakhshi (2019) theoretically investigated the electronic and adsorption properties of Altretamine over the $\mathrm{BN}$ nano ring $[\mathrm{BNNR}(9,9-5)]$ and the AlN nano ring [AlNNR(9,9-5)] in the solvent phase. In 2019, the binding of Altretamine with bovine serum albumin and its inhibitory effect on fibrillation of the protein were studied by Ghosh et al., (2019). Furthermore, Hassanzadeh et al. (2016) analyzed encapsulation of Thiotepa and Altretamine as neurotoxic anticancer drugs in the cucurbit $[n]$ uril $(n=7,8)$ nanocapsules using quantum chemical calculations. Finally, the preparation, characterization and optimization of Altretamine-loaded solid lipid nanoparticles using the Box-Behnken design and the response surface methodology were conducted in 2016 (Gidwani \& Vyas, 2016).

The objective of the present work is to investigate the interactions between the anticancer drug ALT and some mono- and divalent metal cations, such as $\mathrm{Li}^{+}, \mathrm{Na}^{+}, \mathrm{K}^{+}, \mathrm{Be}^{2+}$, $\mathrm{Mg}^{2+}$ and $\mathrm{Ca}^{2+}$. The importance of these ions has been clearly demonstrated in several functions of living systems, such as enzyme regulation, biological membrane stabilization and the transport of glucides and amino acids to proteins through transmembrane channels (Rulíšek \& Havlas, 2000; Fraústo da Silva \& Williams, 2001; Marino et al., 2000; Shui et al., 1998). In the present article, we have evaluated the effect of cation $-\pi$ interactions on the geometrical parameters, the interaction energies and the topological properties of the obtained complexes. For this purpose, a detailed DFT study was conducted at the M06-2X/6-311++G(d,p) level of theory. In addition, the topological and natural bond orbital analyses with $A I M$ and $N B O$ programs were carried out to study the nature of the bonding. To gain further insight into the stability and reactivity of the calculated complexes, molecular orbital properties, such as the highest occupied molecular orbital (HOMO), the lowest unoccupied molecular orbital (LUMO) and the energy gap $\left(E_{\mathrm{g}}\right)$, have been investigated.

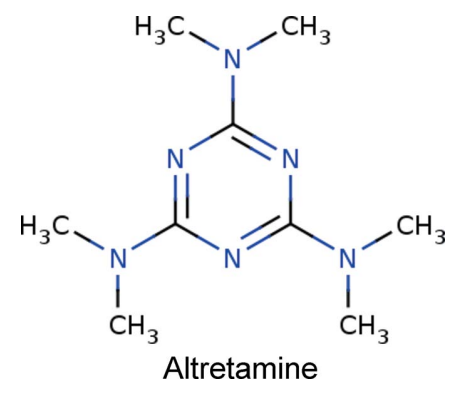

\section{Computational details}

In this work, all of the computations on complexes were carried out using the M06-2X functional (as implemented in GAUSSIAN03; Frisch et al., 2003) and the 6-311++G(d,p) basis set. This method has been proven to be reliable for the study of noncovalent complexes (Zhao et al., 2005, 2006; Zhao \& Truhlar, 2006, 2007, 2008). The optimization was performed, along with a frequency calculation, for each complex to characterize the stationary points and to compute the zero point vibrational energy (ZPVE) corrections. The solvent influence was also determined for water and $\mathrm{CCl}_{4}$ solutions, using the polarizable continuum model (PCM) (Tomasi et al., 2002). The interaction energy $(\Delta E)$ is derived from the difference between the energies in the complex and their monomers. Hence, $\Delta E$ can be evaluated as follows:

$$
\Delta E=E_{\text {cation }-\pi}-\left(E_{\text {cation }}+E_{\pi-\text { system }}\right)
$$

where $E_{\text {cation- } \pi}$ is the total energy of the complex and $E_{\text {cation }}$ and $E_{\pi \text {-system }}$ are the total energies of the cation and Altretamine monomers, respectively. Basis set superposition error (BSSE) (Boys \& Bernardi, 1970) introduces a significant correction in the calculation of energies. The topological analysis of electron density was carried out with AIM theory (Bader, 1990) using the AIM2000 program (Biegler-König et al., 1982, 2000). Natural bond orbital (NBO) analysis (Reed et al., 1988$)$ was also performed to calculate the charge transfer and the natural population analysis of complexes at the M06$2 \mathrm{X} / 6-311++\mathrm{G}(\mathrm{d}, \mathrm{p})$ level of theory using the $N B O$ program (Glendening et al., 1992) within the GAUSSIAN03 package. Furthermore, the molecular orbital energy and the quantum molecular descriptors, such as the energy gap $\left(E_{\mathrm{LUMO}}-\right.$ $E_{\text {Hомо }}$, softness (S), global hardness $(\eta)$ (Pearson, 1997), electronic chemical potential $(\mu)$ (Chattaraj \& Poddar, 1999), electrophilicity index $(\omega)$ (Parr et al., 1999) and electronegativity $(\chi)$ (Sen \& Jorgensen, 1987) ( $\chi$ is identified as the 
negative of $\mu$, as follows: $\chi=-\mu$ ), were analyzed. These properties can be estimated using the HOMO and LUMO energies as follows:

$$
\begin{gathered}
\eta=\frac{E_{\mathrm{LUMO}}-E_{\mathrm{HOMO}}}{2} \\
\mu=\frac{\left(E_{\mathrm{LUMO}}+E_{\mathrm{HOMO}}\right)}{2} \\
\omega=\frac{\mu^{2}}{2 \eta} \\
S=\frac{1}{2 \eta}
\end{gathered}
$$

\section{Results and discussion}

\subsection{Molecular geometry and interaction energy}

The structure of ALT- $M\left(M=\mathrm{Li}^{+}, \mathrm{Na}^{+}, \mathrm{K}^{+}, \mathrm{Be}^{2+}, \mathrm{Mg}^{2+}\right.$ and $\mathrm{Ca}^{2+}$ ) complexes are illustrated according to the position of the cations $(M)$ with respect to the Altretamine ring (Fig. 1). It is well established from the calculations that the size of the cation and the character of the $\pi$-system (ALT) are two factors which have an effect on the strength of these interactions. In the present study, the cation $-\pi$ interactions are categorized into two types. There are different characters for the interaction of the $\pi$-system with the alkali $\left(\mathrm{Li}^{+}, \mathrm{Na}^{+}\right.$and $\left.\mathrm{K}^{+}\right)$and alkaline-earth $\left(\mathrm{Be}^{2+}, \mathrm{Mg}^{2+}\right.$ and $\left.\mathrm{Ca}^{2+}\right)$ metal cations. However, because the goal of this section is an analysis of the influence of the cation- $\pi$ interactions on some of the structural and electronic properties of the ALT ring, all the metal cations are located above the ring centre of the $\pi$-system along the main symmetry axis $\left(C_{3 \mathrm{v}}\right)$.

The experimental data (Bullen et al., 1972), optimized geometrical parameters and estimated errors on the geometrical factors of the ALT complexes are given in Table 1. As observed in this Table, complexation changes the structural parameters of the ALT ring. For instance, the maximum values of the cyclic $\mathrm{C}-\mathrm{N}$ bond lengths $\left(d_{\mathrm{C} 2-\mathrm{N} 1}\right.$ and $\left.d_{\mathrm{C} 2-\mathrm{N} 3}\right)$ correspond to the highest $\left|\Delta E_{\text {ion- } \pi}\right|$ value (see Tables 1 and 2). In contrast, a reverse relationship is found between the exocyclic $\mathrm{C}-\mathrm{N}$ bond length $\left(d_{\mathrm{C} 2=\mathrm{N} 7}\right)$ and $\left|\Delta E_{\mathrm{ion}-\pi}\right|$. Our theoretical results also show that in the ALT monomer, the calculated $\mathrm{N}-\mathrm{C}-\mathrm{N}, \mathrm{C}-\mathrm{N}-\mathrm{C}$ and $\mathrm{N}-\mathrm{C}-\mathrm{N}-\mathrm{C}$ angles $\left(\theta_{\mathrm{N} 1-\mathrm{C} 2-\mathrm{N} 3}\right.$, $\theta_{\mathrm{C} 2-\mathrm{N} 7-\mathrm{C} 9}$ and $\left.\varphi_{\mathrm{N} 1-\mathrm{C} 2-\mathrm{N} 3-\mathrm{C} 4}\right)$ are $125.5,120.8$ and $1.5^{\circ}$, respectively. It is apparent from Tables 1 and 2 that the $\theta_{\mathrm{N} 1-\mathrm{C} 2-\mathrm{N} 3} /$ $\theta_{\mathrm{C} 2-\mathrm{N} 7-\mathrm{C} 9}$ values decrease/increase with increasing $\left|\Delta E_{\mathrm{ion}-\pi}\right|$ in the investigated complexes. Furthermore, as shown in Table 1, the obtained geometrical parameters for the ALT monomer are in good agreement with the experimental data. The calculations also reveal that the distance between the ions and the $\mathrm{C}$ and $\mathrm{N}$ atoms of the ALT ring is not identical in the related complexes. The distance between the ions and the $\mathrm{N}$ atoms is less than that of the $\mathrm{C}$ atoms. According to the obtained results, the ALT ring is not flat in the studied complexes $\left(\varphi_{\mathrm{NCNC}} \neq 0.0^{\circ}\right)$. The $\mathrm{Li}^{+}, \mathrm{Na}^{+}, \mathrm{K}^{+}$and $\mathrm{Ca}^{2+}$ complexes show little deformation of the ALT ring. On the other hand, the $\mathrm{Be}^{2+}$ and $\mathrm{Mg}^{2+}$ complexes reveal a chair-like ring disposition. As is obvious from Tables 1 and 2, the greatest $\left|\Delta E_{\text {ion- } \pi}\right|$ value is associated with the maximum $\varphi_{\mathrm{NCNC}}$ value of the complexes.

It is also noticeable from Table 2 that the absolute value of the interaction energy, i.e. $\left|\Delta E_{\text {ion- } \pi}\right|$, in the divalent $\left(\mathrm{Be}^{2+}\right.$, $\mathrm{Mg}^{2+}$ and $\mathrm{Ca}^{2+}$ ) complexes is higher than in the monovalent $\left(\mathrm{Li}^{+}, \mathrm{Na}^{+}\right.$and $\left.\mathrm{K}^{+}\right)$complexes. Hence, the cation- $\pi$ interaction in the divalent complexes is stronger than in the monovalent complexes. The dependence between the values of $\left|\Delta E_{\text {ion- }-\pi}\right|$ and $d_{\text {ion- } \pi}$ (the distance between the ion and the centre of the ALT ring) can be considered with regard to the cation (alkali or alkaline earth). As can be seen in Tables 1 and 2, the increment of $\left|\Delta E_{\text {ion- } \pi}\right|$ is associated with a decrease of $d_{\text {ion- } \pi}$. The minimum and maximum values of the ion- $\pi$ distance correspond to the $\mathrm{Be}^{2+}$ and $\mathrm{K}^{+}$complexes, respectively. For alkali and alkaline-earth metal cations, as the ionic radius increases, the interaction energy decreases and the equilibrium distance of the cation- $\pi$ interaction $\left(d_{\text {ion }-\pi}\right)$ is found to increase.
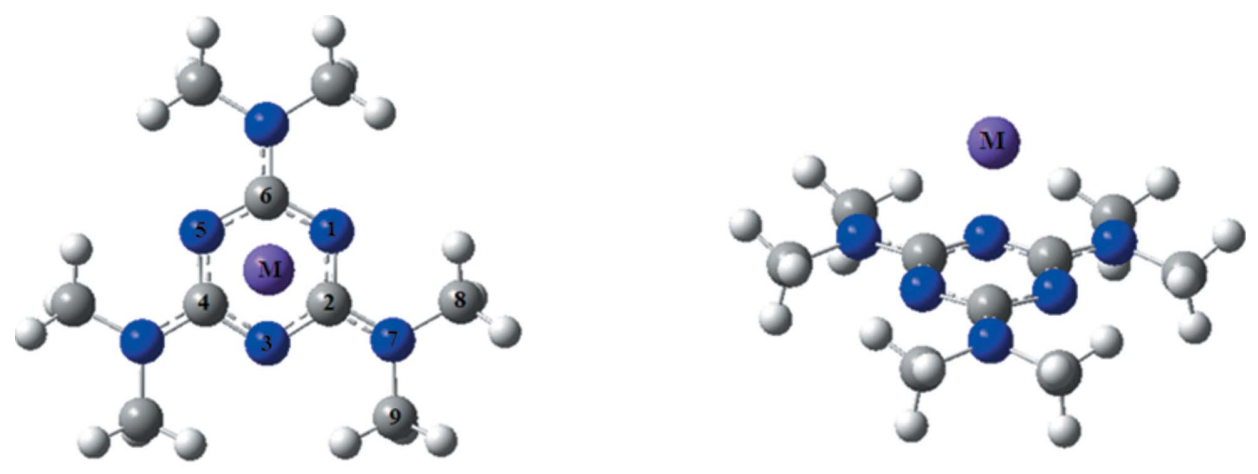

Figure 1

Hydrogen
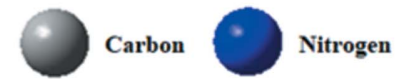

The model representation for the ALT- $M$ derivatives, with $M=\mathrm{Li}^{+}, \mathrm{Na}^{+}, \mathrm{K}^{+}, \mathrm{Be}^{2+}, \mathrm{Mg}^{2+}$ and $\mathrm{Ca}^{2+}$. 
Table 1

Geometrical parameters [bond lengths $(d)$ in $\AA$ and bond angles $(\theta, \varphi)$ in ${ }^{\circ}$ ] calculated by the M06-2X method with the $6-311++\mathrm{G}(\mathrm{d}, \mathrm{p})$ basis set.

EXP refers to experimental data and \%Error is related to the estimated errors on the theoretical and experimental geometrical parameters.

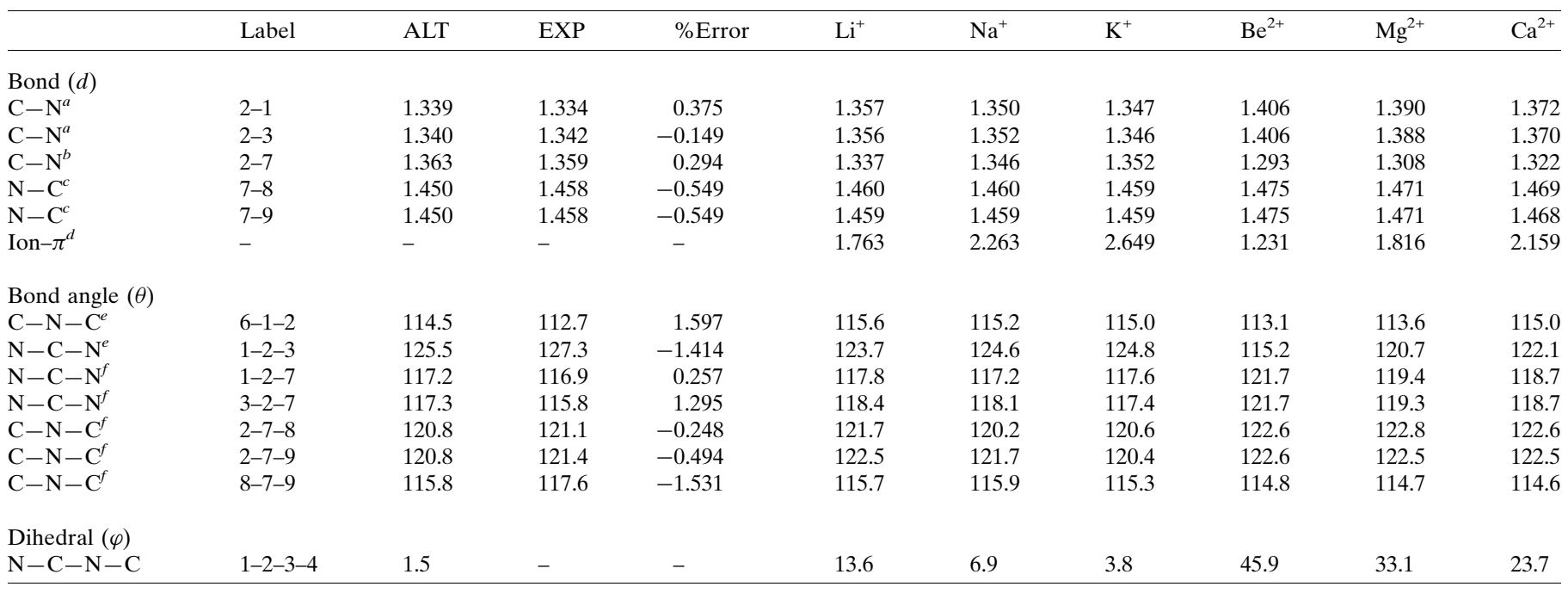

Notes: (a) the cyclic $\mathrm{C}-\mathrm{N}$ bond length; $(b)$ the exocyclic $\mathrm{C}-\mathrm{N}$ bond length; $(c)$ the $\mathrm{C}($ methyl $)-\mathrm{N}$ bond length; $(d)$ the distance between the ion and the centre of the ALT ring; $(e)$ the bond angles inside the ring; $(f)$ the bond angles outside the ring.

The fact that electrostatic attraction is the major contributor to the cation $-\pi$ interaction can be clearly seen from a study of the binding of the metal cations with the aromatic ring. Intermolecular forces of attraction between the molecule and ion hold them together. Electrostatically, it can be conceptualized as the interaction of a positively charged ion with the negative electrostatic potential surface of the ring (Cubero et al., 1998). A more negative electrostatic charge over the centre of the ring leads to stronger cation $-\pi$ binding energies in the studied complexes. A $\pi$-system focuses partial negative charge above and below the plane of the ring. A cation can interact favourably with this partial negative charge when the cation is near the face of the $\pi$-system. In the most stable arrangment, the cation is centred directly over the $\pi$ system and is in direct van der Waals contact with it. Small ions with high charge density form stronger cation $-\pi$ complexes than larger ions.

Garau et al. (2004) also showed that molecules with negligible permanent quadrupole moment values $\left(Q_{z z}\right)$ can interact favourably with different cations. The strength of the cation $-\pi$

\section{Table 2}

The interaction energies $\left(\Delta E_{\mathrm{ion}-\pi}\right.$, in $\left.\mathrm{kJ} \mathrm{mol}^{-1}\right)$, stretching frequency information for the ion $-\pi$ contact $\left(\nu_{\text {ion- }-\pi}\right.$ and $\mathrm{I} R_{\text {ion- }-\pi}$, in $\mathrm{cm}^{-1}$ ), values of the quadrupole moment $\left(Q_{z z}\right.$, in $\left.\mathrm{B}\right)$, polarizibility $\left(\alpha_{z z}\right.$, in $\left.\mathrm{B}^{3}\right)$ and dipole moment $\left(\mu^{\circ}\right.$, in Debye) obtained at the M06-2X/6-311++G(d,p) level of theory.

\begin{tabular}{lllrlll}
\hline & $\Delta E_{\text {ion }-\pi}$ & $v_{\text {ion }-\pi}$ & $\mathrm{I} R_{\text {ion }-\pi}$ & \multicolumn{1}{l}{$Q_{z Z}$} & $\alpha_{z z}$ & $\mu^{\circ}$ \\
\hline $\mathrm{ALT}$ & - & - & - & -94.35 & 160.69 & 0.74 \\
$\mathrm{Li}^{+}$ & -183.88 & 421.50 & 156.89 & -78.51 & 161.86 & 4.05 \\
$\mathrm{Na}^{+}$ & -131.86 & 223.46 & 66.57 & -72.78 & 161.41 & 5.85 \\
$\mathrm{~K}^{+}$ & -110.79 & 177.95 & 25.68 & -74.27 & 165.86 & 6.80 \\
$\mathrm{Be}^{2+}$ & -1193.50 & 717.20 & 216.10 & -75.72 & 155.04 & 1.08 \\
$\mathrm{Mg}^{2+}$ & -668.16 & 426.23 & 126.33 & -61.84 & 164.73 & 6.50 \\
$\mathrm{Ca}^{2+}$ & -487.51 & 361.39 & 64.39 & -60.63 & 168.96 & 8.82 \\
\hline
\end{tabular}

interactions depends strongly on the $Q_{z z} M$ and molecular polarizability $\left(\alpha_{z z}\right)$ values of the aromatic compound (Ebrahimi et al., 2012). In fact, the cation $-\pi$ interaction arises from the electrostatic interaction between a monopole (cation) and a quadrupole ( $\pi$-system). To design a strong cation- $\pi$ interaction, the aromatic ring should have a large and negative quadrupole moment and a small molecular polarizability (Frontera, 2013). The densities of the electronic clouds of the aromatic molecule play a very important role in these interactions. This can be attributed to the $Q_{z z}$ value of the aromatic ring. To have a large value of $Q_{z z}$, the use of electron-donating groups is required. The electron-donating (or electron-withdrawing) effects of the groups lead to an increase (or decrease) in the $\pi$-electron density of the aromatic ring and thereby enhance (or reduce) the $Q_{z z}$ value of the $\pi$-system (Raju et al., 2011). In the ALT monomer, the value of $Q_{z z}$ is -94.35 B (Buckinghams; $1 \mathrm{~B}=3.336 \times 10^{-40} \mathrm{C} \mathrm{m}^{2}$ ), i.e. it is able to $\pi$-interact favourably with cations. This can be related to the $N$-methyl electron-donating groups, which increase the $Q_{z z}$ value of the ring. Therefore, the formed interactions become favourable if the $\mathrm{N}$ atoms of ALT are coordinated to the metal cations.

It is obvious from Table 2 that the value of $\left|Q_{z z}\right|$ for these complexes decreases as the size of the alkali-metal cation increases from $\mathrm{Li}^{+}$to $\mathrm{Na}^{+}$(except for the $\mathrm{K}^{+}$complex). Similar results have been obtained for alkaline-earth metal cations (from $\mathrm{Be}^{2+}$ to $\mathrm{Ca}^{2+}$ ). On the other hand, molecules with lesser electronegativity and larger radii have greater polarizability. The polarizability is the second derivative of the energy with respect to an applied electric field (Řeha et al., 2002). As observed in Table 2, the $\mathrm{K}^{+}$and $\mathrm{Ca}^{2+}$ complexes have higher polarizabilities in each group. This means that these complexes create the weaker interactions $\left(\Delta E_{\text {ion- } \pi}\right)$ with respect to the other complexes. 
Table 3

Selected topological parameters of ALT complexes (in a.u.) calculated at the M06-2X/6-311++G(d,p) level of theory.

\begin{tabular}{lcccccrc}
\hline & $\rho_{\mathrm{C} 2-\mathrm{N} 3}{ }^{a}$ & $\rho_{\mathrm{C} 2-\mathrm{N} 7}{ }^{b}$ & $\rho_{\mathrm{C}-\mathrm{H}}$ & $\rho_{\text {ion-N }}$ & $\nabla^{2} \rho_{\text {ion-N }}$ & $\mathrm{H}_{\text {ion-N }}$ & $-\mathrm{G}_{\mathrm{C}} / \mathrm{V}_{\mathrm{C}}$ \\
\hline $\mathrm{Li}^{+}$ & 0.3303 & 0.3345 & 0.2847 & 0.0209 & 0.1182 & 0.0053 & 1.2801 \\
$\mathrm{Na}^{+}$ & 0.3349 & 0.3300 & 0.2844 & 0.0135 & 0.0695 & 0.0036 & 1.3525 \\
$\mathrm{~K}^{+}$ & 0.3369 & 0.3265 & 0.2835 & 0.0126 & 0.0532 & 0.0025 & 1.2953 \\
$\mathrm{Be}^{2+}$ & 0.2999 & 0.3632 & 0.2856 & 0.0747 & 0.3551 & -0.0084 & 0.9204 \\
$\mathrm{Mg}^{2+}$ & 0.3101 & 0.3530 & 0.2856 & 0.0368 & 0.1979 & 0.0048 & 1.1209 \\
$\mathrm{Ca}^{2+}$ & 0.3205 & 0.3443 & 0.2848 & 0.0344 & 0.1380 & 0.0010 & 1.0318 \\
\hline
\end{tabular}

Notes: $(a)$ cyclic $\rho_{\mathrm{C} 2-\mathrm{N} 3} ;(b)$ exocyclic $\rho_{\mathrm{C} 2-\mathrm{N} 7}$.

Another index closely related to the strength of the interaction energy is the shifting of the cation $-\pi$ stretching frequencies. It is important to emphasize that with strengthening cation $-\pi$ interactions, the stretching frequencies shift to higher wavenumbers (Khanmohammadi et al., 2014). The data presented in Table 2 indicate that the stretching frequency of the cation $-\pi$ contact decreases as the atomic radius of the metal ion increases. This is in accordance with the binding strength of the metal cation. The interaction energy data suggest that the nature of the complexation of the divalent cations with the ligand could be different from that of the monovalent cations, and that forces other than electrostatic forces may play a vital role in stabilizing these complexes.

From an analysis of several organometallic mono- (Stanghellini et al., 2006) and divalent (Schäfer et al., 1971; Cyvin et al., 1970, 1971; Brunvoll et al., 1971) complexes it can be concluded that frequency changes during complexation are not due to significant differences between the force constants for both the free and complexed molecules, but to weak

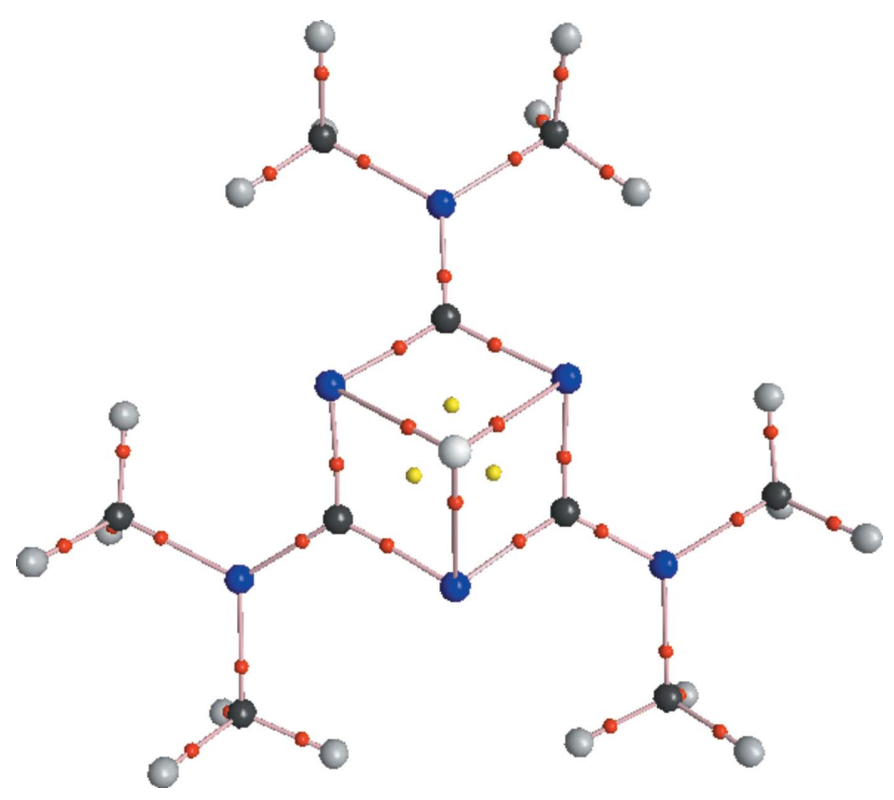

Figure 2

Schematic representation of the distribution of critical points in the ALT-Be ${ }^{2+}$ complex. Small red spheres, small yellow spheres and lines represent bond critical points (BCPs), ring critical points (RCPs) and bond paths, respectively. kinematic coupling between the monomer and metal-ring skeletal modes in the complexes (Stanghellini et al., 2006). Generally, the frequency differences between the various complexes can be attributed to changes in the electronic charge distribution resulting from metal-atom coordination (Stanghellini et al., 2006) and the mass of the central metal atom (Cyvin et al., 1970). The stretching frequencies of the ion $-\pi$ interaction $\left(\nu_{\text {ion }-\pi}\right)$ for the investigated complexes are shown in Table 2. It can be seen in this Table that the increment in the absolute value of the interaction energies, i.e. $\left|\Delta E_{\mathrm{ion}-\pi}\right|$, is accompanied by an increase in the vibrational frequency $\left(v_{\text {ion- }-\pi}\right)$ value. The obtained results reveal that the minimum and maximum values of the vibrational parameters of $v_{\text {ion }-\pi}$ belong to the monovalent and divalent complexes, respectively.

The IR spectra $\left(\mathrm{IR}_{\mathrm{ion}-\pi}\right)$ of the ALT complexes were also predicted theoretically from the calculated intensities (see Table 2). As seen in this Table, the IR spectra of the monovalent complexes show a weaker band in comparison with those of the divalent complexes. Our findings also show that the highest $\mathrm{IR}_{\mathrm{ion}-\pi}$ value belongs to the $\mathrm{Be}^{2+}$ complex, while the lowest corresponds to the $\mathrm{K}^{+}$complex. In fact, the upper frequency shift of this band in the $\mathrm{Be}^{2+}$ complex $\left(216.10 \mathrm{~cm}^{-1}\right)$ suggests more stretching character for the ion $-\pi$ contact in the related complex.

\subsection{AIM analysis}

The theory of 'Atoms in Molecules' (AIM) (Bader, 1990, 1991, 1998) has been applied to analyze the chemical bond and its strength in term of electron-density distribution. The calculated topological parameters of the complexes, such as charge density $(\rho)$, its Laplacian $\left(\nabla^{2} \rho\right)$, the total electron energy density $\left(\mathrm{H}_{\mathrm{C}}\right)$ and its components $\left(\mathrm{G}_{\mathrm{C}}\right.$, kinetic electron energy density, and $\mathrm{V}_{\mathrm{C}}$, potential electron energy density) at the bond critical point (BCP), are given in Table 3. In AIM analysis, the Laplacian sign is exploited to determine closedshell and shared-shell interactions. For instance, in covalent bonds (shared-shell interactions), the Laplacian of the charge density, $\nabla^{2} \rho$, is negative in the critical point. In contrast, it becomes positive for the closed-shell interactions (Bader, 1990; Bader et al., 1992). It is also worth mentioning that if $\nabla^{2} \rho$ $>0$ and $\mathrm{H}_{\mathrm{C}}<0$, then the interactions are at least partly covalent (Pacios, 2004; Jenkins \& Morrison, 2000; Arnold \& Oldfield, 2000; Rozas et al., 2000).

The calculations of the electron density reveal that the ALT complexes have low $\rho_{\text {ion-N }}$ values, $\nabla^{2} \rho_{\text {ion-N }}>0$ and $\mathrm{H}_{\text {ion-N }}>0$. This feature is characteristic for closed-shell interactions. In the $\mathrm{Be}^{2+}$ complex, the corresponding $\mathrm{H}_{\text {ion-N }}$ value is negative, which indicates that this interaction is at least partly covalent (see Table 3). This result can be attributed to the small ionic radius and the high ionization potential of the $\mathrm{Be}^{2+}$ ion with respect to the other ions. It is also worth mentioning that the $-\mathrm{Gc} / \mathrm{Vc}$ ratio can be applied as a criterion for the nature of the ion $-\pi$ interactions: for $-\mathrm{Gc} / \mathrm{Vc}>1$, the interaction is noncovalent, while for $0.5<-\mathrm{Gc} / \mathrm{Vc}<1$, it is partly covalent. As shown in Table 3, the obtained values also confirm that the 
Table 4

$E^{(2)}$ corresponds to charge transfer between $\sigma_{(\mathrm{C}-\mathrm{N})}$ and $\mathrm{Lp}^{*}$ (cation) (in $\mathrm{kcal} \mathrm{mol}{ }^{-1}$ ), occupation numbers of donor (O.N. ${ }_{\mathrm{D}}$ ) and acceptor (O.N. $\left.{ }_{\mathrm{A}}\right)$ orbitals, the atomic charges of cations in complexes $\left(\mathrm{q}_{M}\right)$ and the charge transfer $\left(\Delta \mathrm{q}_{\mathrm{CT}}\right.$ in e $)$ in the studied complexes.

\begin{tabular}{lccccr}
\hline & $\sigma_{(\mathrm{C}-\mathrm{N})} \rightarrow \mathrm{Lp}^{*}$ (cation) & O.N.D & O.N.A & $\mathrm{q}_{M}$ & \multicolumn{1}{c}{$\Delta \mathrm{q}_{\mathrm{CT}}$} \\
\hline $\mathrm{ALT}$ & - & - & - & - & - \\
$\mathrm{Li}^{+}$ & 5.27 & 1.9793 & 0.0273 & 0.384 & 0.616 \\
$\mathrm{Na}^{+}$ & 2.77 & 1.9801 & 0.0192 & 0.754 & 0.246 \\
$\mathrm{~K}^{+}$ & 1.65 & 1.9798 & 0.0140 & 1.077 & -0.077 \\
$\mathrm{Be}^{2+}$ & 12.59 & 1.9588 & 0.0687 & 0.034 & 2.034 \\
$\mathrm{Mg}^{2+}$ & 4.60 & 1.9775 & 0.0177 & 0.604 & 1.396 \\
$\mathrm{Ca}^{2+}$ & 2.51 & 1.9801 & 0.0189 & 1.311 & 0.689 \\
\hline
\end{tabular}

$\mathrm{Be}^{2+}$ complex is partly covalent, while the remainder are noncovalent. The calculated molecular graph of the ALT-Be ${ }^{2+}$ complex is shown in Fig. 2. As represented in this figure, the bond paths are detected between metal cations and each $\mathrm{N}$ atom of the ring in the related complexes.

It can be seen in Table 3 that the electron-density values increase for cation $-\pi$ interactions in the following order: $\mathrm{Li}^{+}>$ $\mathrm{Na}^{+}>\mathrm{K}^{+}$for the alkali complexes and $\mathrm{Be}^{2+}>\mathrm{Mg}^{2+}>\mathrm{Ca}^{2+}$ for the alkaline-earth complexes. In other words, for each ion group (alkali or alkaline-earth), the smallest cation has the highest value of $\rho$ at the BCP and vice versa. In the studied complexes, it is observed that reduction of the electron density is associated with weakening of the interaction energy and elongation of the ion- $\pi$ distance. These consequences obviously show the strength of the cation $-\pi$ interactions. Furthermore, for the alkali and alkaline-earth metal cations, as the atomic size of the cation increases, the values of the Laplacian are found to decrease (see Table 3). A good relationship can be observed between the interaction energy $\left(\left|\Delta E_{\text {ion- } \pi}\right|\right)$ values with the electron densities of $\rho_{\text {ion-N }}$ and its Laplacian, $\nabla^{2} \rho_{\text {ion-N }}$ in Fig. 3. For these dependences, the regression coefficients (R) are 0.988 and 0.982 , respectively. Therefore, it can be concluded that the electron-density values may be an important parameter for the evaluation of the strength of ion $-\pi$ interactions.

In order to analyze the nature and strength of the cation $-\pi$ interactions, other topological parameters of these systems have also been investigated. It is obvious from Table 3 that the $\left|\Delta E_{\text {ion- } \pi}\right|$ values increase with decreasing $\rho_{\mathrm{C} 2-\mathrm{N} 3}$ values of the ring. In addition, the increment of the $\mathrm{BCP}$ value of the exocyclic $\mathrm{C}-\mathrm{N}$ bonds $\left(\rho_{\mathrm{C} 2-\mathrm{N} 7}\right)$ is found to be in the order $\mathrm{Li}^{+}$ $>\mathrm{Na}^{+}>\mathrm{K}^{+}$for the alkali metal complexes and $\mathrm{Be}^{2+}>\mathrm{Mg}^{2+}>$ $\mathrm{Ca}^{2+}$ for the corresponding alkaline-earth metal complexes. These results are in accordance with the cation $-\pi$ interactions. In addition, there is a reverse relationship between the values of $\rho_{\mathrm{C} 2-\mathrm{N} 3}$ and $\rho_{\mathrm{C} 2-\mathrm{N} 7}$ with their corresponding bond lengths (see Tables 1 and 3).

\subsection{Charge transfer (NBO analysis)}

NBO analysis offers a method for exploring intermolecular bonding and charge transfer in molecular structures (Reed $e t$ al., 1988). Table 4 shows the donor-acceptor energies, $E^{(2)}$, and the occupancy of species calculated at the M06-2X/6-

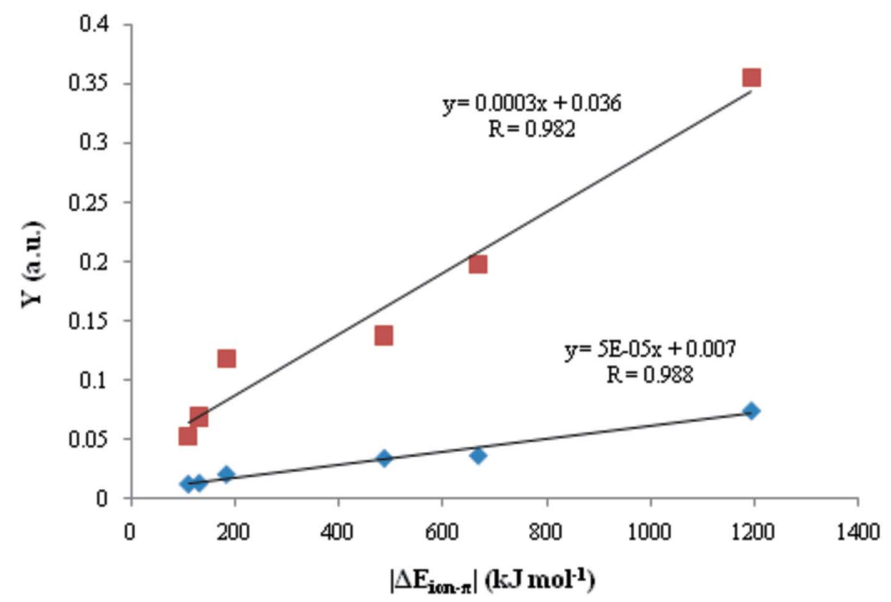

Figure 3

Correlation between the $\rho_{\text {ion-N }}$ (marked with filled-diamond symbols) and $\nabla^{2} \rho_{\text {ion-N }}$ (marked with filled-square symbols) values (Y) versus the $\left|\Delta E_{\text {ion- } \pi}\right|$ for the ALT- $M$ complexes.

$311++\mathrm{G}(\mathrm{d}, \mathrm{p})$ level of theory. As observed in Table 4, the most significant change in the occupancies of $\sigma_{(\mathrm{C}-\mathrm{N})}$ and $\mathrm{LP}^{*}$ (cation) comes from the $\sigma_{(\mathrm{C}-\mathrm{N})} \rightarrow \mathrm{LP}^{*}{ }_{\text {(cation) }}$ interaction. The theoretical results show that $\sigma_{(\mathrm{C}-\mathrm{N})}$ of the ALT ring acts as a donor and the $\mathrm{LP}^{*}$ (cation) acts as an acceptor. The smallest and greatest values of $E^{(2)}$ correspond to the $\mathrm{K}^{+}$and $\mathrm{Be}^{2+}$ complexes, respectively (see Table 4). The data also demonstrate that the $E^{(2)}$ values for the divalent complexes are greater than for the monovalent complexes, which is in agreement with the stronger cation $-\pi$ interactions for these complexes. It should be noted that the interaction between the cations and the $\pi$-system is reduced with increasing atomic number and the size of the metal cations from top to bottom in each group.

As stated above, there is a charge transfer from the aromatic system (electron donor) to the metallic ions (electron acceptor). The calculations reveal that the stronger

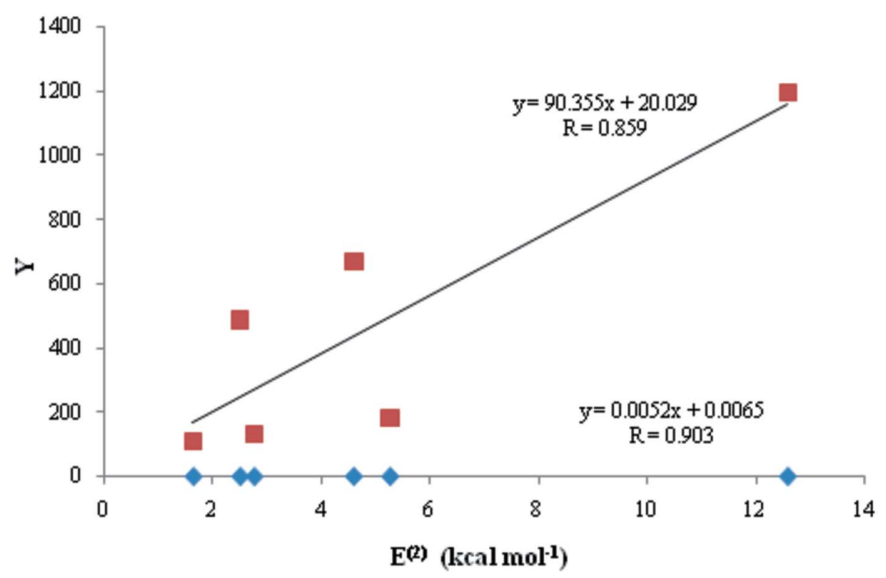

Figure 4

Correlation between the $\rho_{\text {ion- } \mathrm{N}}$ (in a.u., marked with filled-diamond symbols) and $\left|\Delta E_{\text {ion- } \pi}\right|$ (in $\mathrm{kJ} \mathrm{mol}^{-1}$, marked with filled-square symbols) values (Y) versus the $E^{(2)}$ for the ALT- $M$ complexes. 
interactions of each group of complexes $\left(\mathrm{Li}^{+}\right.$and $\left.\mathrm{Be}^{2+}\right)$ lead to a larger increase in the occupation number of the $\mathrm{LP}^{*}$ (cation) and a larger decrease in the $\sigma_{(\mathrm{C}-\mathrm{N})}$ occupation number. In fact, more charge transfer occurs from $\sigma_{(\mathrm{C}-\mathrm{N})}$ of the ALT ring to $\mathrm{LP}^{*}$ of the metal cations because of the large variation in the electron density at the $\mathrm{C}-\mathrm{N}$ bond critical points of the $\pi$-system. In addition, the calculations show that the increase in the $E^{(2)}$ value is accompanied by an increase in the $\left|\Delta E_{\text {ion- } \pi}\right|$ and $\rho_{\text {ion-N }}$ values (see Tables 2-4). As shown in Fig. 4, there are relatively good correlations between the values of $\rho_{\text {ion-N }}$ and the interaction energies $\left(\left|\Delta E_{\text {ion- } \pi}\right|\right)$ versus the donoracceptor energies $\left[E^{(2)}\right]$, with correlation coefficients of 0.903 and 0.859 , respectively.

The values of charge transfer $\left(\Delta q_{\mathrm{CT}}\right)$ for the investigated complexes are also listed in Table 4. In the ALT complexes, the values of charge transfer can be evaluated from the difference between the charge of the isolated cation and the atomic charge of the cation in the complex. The results show that, with the exception of $\mathrm{K}^{+}$, the atomic charges of the cations in the complexes $\left(\mathrm{q}_{M}\right)$ are smaller than for the isolated cations (see Table 4). A comparison between the $\mathrm{Li}^{+}, \mathrm{Na}^{+}$and $\mathrm{K}^{+}$cations shows that the charge transfer from the $\sigma_{\mathrm{C}-\mathrm{N}}$ of the ALT ring to the $\mathrm{Li}^{+}$cation is the greatest. This result can be supported by the smaller charge on the $\mathrm{Li}^{+}$cation with respect to the $\mathrm{Na}^{+}$and $\mathrm{K}^{+}$cations in the related complexes. Hence, the shorter bond distance in the complex of the smaller cation allows the cation to more effectively withdraw electron density from the $\pi$-system.

It can also be seen that among the divalent metal cations, the greatest charge transfer occurs in the $\mathrm{Be}^{2+}$ complex, while the smallest charge belongs to the $\mathrm{Ca}^{2+}$ complex. Therefore, the charge decrease on the metal cations is found to be in the order $\mathrm{Be}^{2+}>\mathrm{Mg}^{2+}>\mathrm{Ca}^{2+}$ for the corresponding divalent metal complexes. It is also obvious from Table 4 that the charge transfer for the complexes formed by divalent cations is more considerable than that for the complexes involving monovalent cations, suggesting that the cation- $\pi$ interaction in alkaline-earth metal complexes might be stronger than that in alkali metal complexes. As a result, the smaller radius and the greater electron density of the metal ion lead to more charge transfer from the ring to the ion in the analyzed complexes (Ghiassi \& Raissi, 2015; Zaboli \& Raissi, 2015; Khanmohammadi et al., 2014). These results are in agreement with the strength of the cation- $\pi$ interactions. Furthermore, the theoretical outcomes indicate that the orders of $E^{(2)}$ and the charge transfer $\left(\Delta \mathrm{q}_{\mathrm{CT}}\right)$ values during complexation are identical. Therefore, the charge transfer may be a significant characteristic in determining the strength of the ion $-\pi$ interactions.

\subsection{The solvent effect}

In this study, the PCM model (Tomasi et al., 2002) has been applied for investigating the solvent effect on the ALT complexes. The PCM is a more advanced variant of the cavity model. A classical cavity with a shape adapted to the molecule is created by placing a sphere at each atom (possibly with the exception of the $\mathrm{H}$ atoms). This surface is subsequently discretized by dividing it into small triangles. This addresses the shape problem but the radii of the spheres still remain arbitrary (Pascual-Ahuir et al., 1994; Cossi et al., 1996). In order to explore the changes of geometry and the interaction energy in the different ALT complexes, the optimization was carried out in water and $\mathrm{CCl}_{4}$ solutions at the M06-2X/6$311++\mathrm{G}(\mathrm{d}, \mathrm{p})$ level of theory. The geometrical and energetic parameters of the ALT complexes in water and $\mathrm{CCl}_{4}$ solutions are given in Table S1 (see supporting information).

The outcomes display that the effect of solvent leads to significant changes in the geometry of the evaluated complexes. For example, the calculated $d_{\text {ion- } \pi}$ distances are found to increase on going from the gas phase to solution. Moreover, our results indicate that when the solvent effect is utilized, the interaction energies of the complexes are appreciably altered (see Table S1). Theoretical results demonstrate that the interaction energies of the ALT complexes in the gas phase are higher than in the solution phase, and in the nonpolar solvent $\left(\mathrm{CCl}_{4}\right)$ are higher than in the polar solvent (water). Thus, it can be concluded that the stability of the ALT complexes in the solution phase is considerably lower than in the gas phase. Analogous to the gas phase, the $\mathrm{Be}^{2+}$ complex also reveals the strongest interaction in the solution phase with respect to the other complexes. Generally, the outcomes show that the interaction strength of the complexes in the gas phase is greater than in the solution phase. For instance, the interaction energies for the ALT- $\mathrm{K}^{+}$and ALT-Be ${ }^{2+}$ complexes decrease from -110.79 and $-1193.50 \mathrm{~kJ} \mathrm{~mol}^{-1}$ in the gas phase to -40.30 and $-564.07 \mathrm{~kJ} \mathrm{~mol}^{-1}$ in $\mathrm{CCl}_{4}$ solution and to 1.58 and $-101.30 \mathrm{~kJ} \mathrm{~mol}^{-1}$ in water solution, respectively (see Tables 2 and S1). Based on the performed calculations, the energetic preference of the $\mathrm{Be}^{2+}$ complex over the $\mathrm{K}^{+}$complex in $\mathrm{CCl}_{4}$ solvent is greater than in water solvent. This means that the formation of the ALT complexes in the nonpolar solvent is more favourable with respect to the polar solvent, energetically.

AIM and NBO analyses were also employed to discover more about the character of the cation $-\pi$ interactions in the solution phase. The inclusion of the solvent effect in computations demonstrates the important outcomes in the topological features and the charge transfer $\left(\Delta \mathrm{q}_{\mathrm{CT}}\right)$ values during complexation (see Table S1). As observed in this Table, the topological parameters $\left(\rho_{\text {ion-N }}\right.$ and $\left.\nabla^{2} \rho_{\text {ion-N }}\right)$ display fewer variations in the solution phase in comparison with the gas phase. This result is in agreement with the cation $-\pi$ interaction strengths of the studied complexes in the different phases. In other words, the cation $-\pi$ interaction in the solution phase is found to be weaker than that observed for the gas phase. Additionally, an investigation of the charge-transfer values $\left(\Delta \mathrm{q}_{\mathrm{CT}}\right)$ also reveals a weakening of the interactions of the complexes in the solution phase with respect to the gas phase. For example, the charge transferred for the $\mathrm{Be}^{2+}$ complex in the gas phase is $2.034 \mathrm{e}$, which reduces to values of 1.818 and $1.487 \mathrm{e}$ in $\mathrm{CCl}_{4}$ and water solutions, respectively (see Table S1).

The molecular dipole moment $\left(\mu^{\circ}\right)$ is perhaps the simplest experimental measure of charge distribution in a molecule 
Table 5

Values of the HOMO and LUMO energies, energy gap $\left(E_{\mathrm{g}}\right)$, chemical hardness $(\eta)$, electronic chemical potential $(\mu)$, electronegativity $(\chi)$, electrophilicity index $(\omega)$ and softness (S) in terms of $\mathrm{eV}$.

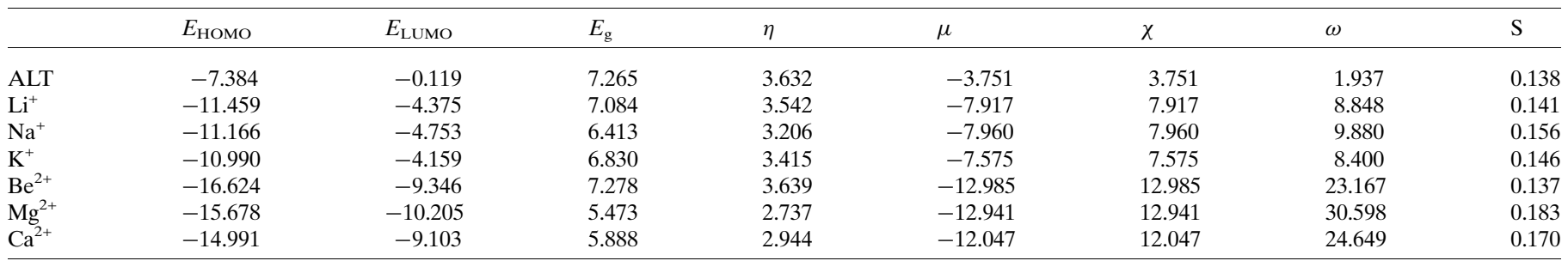

(Glossman-Mitnik, 2007). Significant changes in the dipole moment of the studied complexes are observed when the solvent effect is applied. The increment of dipole moment in going from the gas phase to solution is accompanied by an increase in solvent polarity. The values of the dipole moment for both the gas phase and the solvent media are collected in Tables 2 and S1. It is evident that the dissimilarity between the dipole moments in the investigated complexes depends on the character of the metal cations and the type of solvent. The calculations display that the $\mathrm{Mg}^{2+}$ complex has the largest dipole moment and the $\mathrm{Be}^{2+}$ complex has the smallest (related to water solvent). This consequence may be related to the charge value on the metal cations. For the ALT complexes, the most/least positive charge is observed for the $\mathrm{Mg}^{2+} / \mathrm{Be}^{2+}$ cations, respectively (data not reported). However, the dipole moments indicate that the smallest value is in the gas phase and the greatest value is in water solvent.

\subsection{HOMO-LUMO analysis}

In order to investigate the stability and reactivity of the complexes, we have analyzed the molecular orbital properties and the frontier electron densities. The energy of the HOMO corresponds to the ionization potential ( $\left.\mathrm{IP}=-E_{\mathrm{HOMO}}\right)$ and the LUMO energy depends on the electron affinity $(\mathrm{EA}=$ $\left.-E_{\mathrm{LUMO}}\right)$. The energy gap between HOMO and LUMO $\left(E_{\mathrm{g}}\right)$ is an important parameter to determine the chemical reactivity, optical polarizability and chemical hardness-softness of the molecule (Kosar \& Albayrak, 2011). Fig. 5 shows the distribution and energy levels of the HOMO and LUMO orbitals for the $\mathrm{Be}^{2+}$ complex in the gas phase. The positive and negative phases are red and green, respectively. As revealed in this figure, the HOMO and LUMO of the $\mathrm{Be}^{2+}$ complex are more confined on the ring and electronic projection cannot be seen over the $\mathrm{CH}_{3}$ functional groups of the complex (related to LUMO).

The global indices of reactivity in the context of DFT, such as softness $(\mathrm{S})$, chemical hardness $(\eta)$, electronic chemical potential $(\mu)$, electronegativity $(\chi)$ and global electrophilicity power $(\omega)$, for the ALT complexes are presented in Table 5. It is found that the stability of the chemical species can be attributed to its hardness in accordance with the principle of maximum hardness (Pearson, 1987). The resistance of a chemical substance to change in its electronic arrangement is determined by the chemical hardness (Raissi et al., 2013). The softness is the reciprocal of the hardness which evaluates the facility of charge transfer and its relationship with high polarizability (Raissi et al., 2013). Molecules with higher $E_{\mathrm{g}}$ and hardness are kinetically more stable. Hard and soft molecules have a large and small $E_{\mathrm{g}}$, respectively. Our findings indicate that the $\mathrm{Be}^{2+}$ complex has the highest $E_{\mathrm{g}}$ value, which reveals a greater stability of this complex. On the other hand, the $\mathrm{Mg}^{2+}$ complex, with a lower $E_{\mathrm{g}}$, is the softer and less stable with respect to the others (see Table 5). The electronic chemical potential $(\mu)$ also estimates the resistance of a chemical compound to the loss of electron density (Domingo et al., 2016). It presents a technique to compute the electronegativity $(\chi)$ values for atoms and molecules. The $\mu$ value is known as the negative of the $\chi$ value. The results reveal that for all the title complexes, the values of the electronic chemical potential are negative. This means that the studied complexes are stable. The outcome of calculations also indicates that the

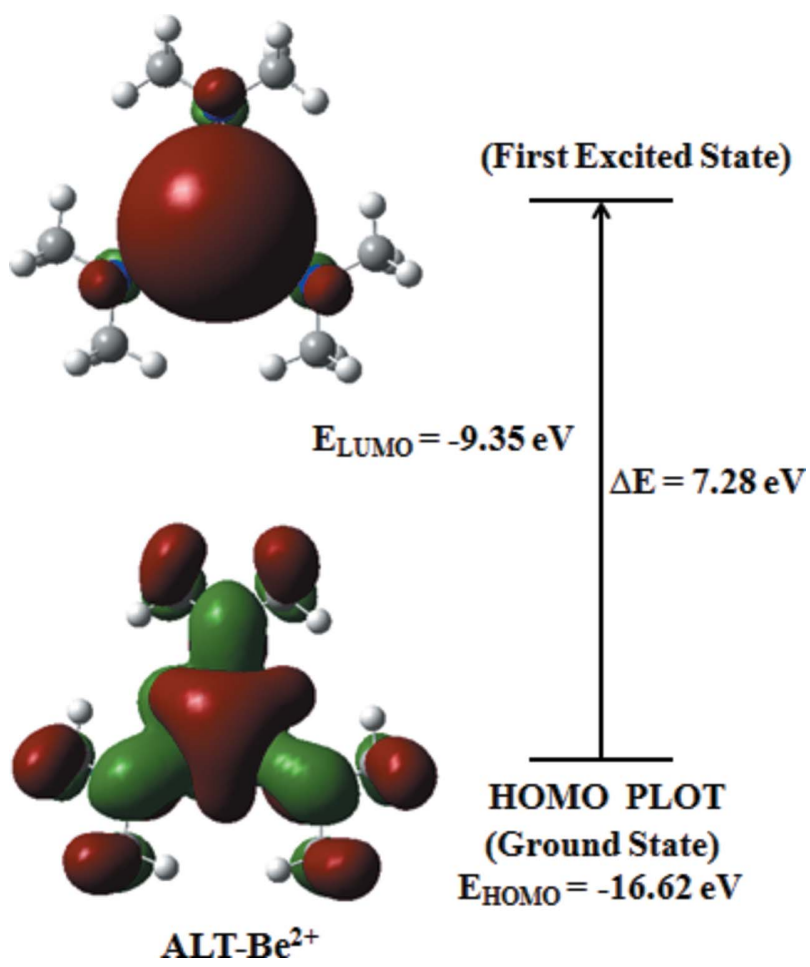

Figure 5

The HOMO and LUMO of the ALT-Be ${ }^{2+}$ complex, as calculated at the M06-2X/6-311++G(d,p) level of theory. 
largest/smallest values of electronic chemical potential belong to the monovalent/divalent complexes.

The electrophilicity index $(\omega)$ demonstrates that a good electrophile is a species described by a high $|\mu|$ value and a low $\eta$ value (Domingo et al., 2016). Based on the classification of the electrophilicity index of a molecule, weak electrophiles show $\omega<0.8 \mathrm{eV}$ and medium electrophiles $0.8<\omega<1.5 \mathrm{eV}$ and strong electrophiles $\omega>1.5 \mathrm{eV}$ (Domingo et al., 2002). As can be seen in Table 5, the minimum and maximum values of the electrophilicity index belong to the $\mathrm{K}^{+}$and $\mathrm{Mg}^{2+}$ ions, respectively. Moreover, the results show that these values increase in the presence of cation $-\pi$ interactions, so that the greatest and smallest values of the electrophilicity index are observed for the divalent and monovalent complexes, respectively.

\section{Conclusions}

In the current work, the effect of cation- $\pi$ interactions on the electronic properties of the complexes formed between the anticancer drug ALT and mono- and divalent $\left(\mathrm{Li}^{+}, \mathrm{Na}^{+}, \mathrm{K}^{+}\right.$, $\mathrm{Be}^{2+}, \mathrm{Mg}^{2+}$ and $\mathrm{Ca}^{2+}$ ) metal cations has been explored in the gas phase and in solution. It is well established from the calculations that the size of the cation and the character of the $\pi$-system (ALT) are two factors which affect the strength of these interactions. The results of DFT calculations show that the strongest and weakest interactions correspond to the $\mathrm{Be}^{2+}$ and $\mathrm{K}^{+}$complexes, respectively. It can be seen that the interaction between the cations and the $\pi$-system are reduced with increasing atomic number and size of the metal cations from top to bottom in each group. Based on an AIM analysis, the ALT complexes have low $\rho_{\text {ion-N }}$ values, $\nabla^{2} \rho_{\text {ion-N }}>0$ and $\mathrm{H}_{\text {ion-N }}>0$. This denotes that these complexes show the characteristics of closed-shell interactions in nature. In the $\mathrm{Be}^{2+}$ complex, the corresponding $\mathrm{H}_{\text {ion- } \mathrm{N}}$ value is negative, which means that this interaction is at least partly covalent. In addition, the results of NBO analysis display a charge transfer from the aromatic system (electron donor) to the metallic ions (electron acceptor). Our theoretical outcomes exhibit that the value of charge transfer decreases as the size of the cation increases. The results also reveal that the interaction energies of the ALT complexes in the gas phase are higher than in the solution phase, and in the nonpolar solvent $\left(\mathrm{CCl}_{4}\right)$ are higher than in the polar solvent (water). Thus, it can be concluded that the stabilities of the ALT complexes in the solution phase are considerably lower than in the gas phase. Significant changes in the dipole moment of the complexes are also observed when the solvent effect is taken into account. The increment of the dipole moments in going from the gas phase to solution is accompanied by an increase of the solvent polarity. Moreover, the molecular orbital results show that the $\mathrm{Be}^{2+}$ complex has the highest $E_{\mathrm{g}}$ value, which reveals the greater stability of this complex, whereas the $\mathrm{Mg}^{2+}$ complex with a lower $E_{\mathrm{g}}$ value is softer and less stable with respect to the others. Several correlations can be observed between the energetic, geometrical and topological parameters. It should be stated that the significance of theoretical models for these interactions in biological systems has allowed us to study them.

\section{Acknowledgements}

The authors wish to thank Payame Noor University of Tehran for their support.

\section{References}

Archambault, F., Chipot, C., Soteras, I., Luque, F. J., Schulten, K. \& Dehez, F. (2009). J. Chem. Theory Comput. 5, 3022-3031.

Armentrout, P. B. \& Rodgers, M. T. (2000). J. Phys. Chem. A, 104, 2238-2247.

Arnold, W. D. \& Oldfield, E. (2000). J. Am. Chem. Soc. 122, 1283512841.

Bader, R., Keith, T., Gough, K. \& Laidig, K. (1992). Mol. Phys. 75, 1167-1189.

Bader, R. F. W. (1990). In Atoms in Molecules: A Quantum Theory. Oxford: Clarendon Press.

Bader, R. F. W. (1991). Chem. Rev. 91, 893-928.

Bader, R. F. W. (1998). J. Phys. Chem. A, 102, 7314-7323.

Biegler-König, F. W., Bader, R. F. W. \& Tang, T. H. (1982). J. Comput. Chem. 3, 317-328.

Biegler-König, F. W., Schonbohm, J., Derdan, R., Bayles, D. \& Bader, R. (2000). AIM2000. Version 2.000. http://www.aim2000.de/.

Boys, S. F. \& Bernardi, F. (1970). Mol. Phys. 19, 553-566.

Brunvoll, J., Cyvin, S. J. \& Schäfer, J. (1971). J. Organomet. Chem. 27, 69-71.

Bullen, G. J., Corney, D. J. \& Stephens, F. S. (1972). J. Chem. Soc. Perkin Trans. 2, pp. 642-646.

Caldwell, J. W. \& Kollman, P. A. (1995). J. Am. Chem. Soc. 117, 41774178.

Černý, J. \& Hobza, P. (2007). Phys. Chem. Chem. Phys. 9, 5291-5303.

Chan, J. K. (2004). Gynecol. Oncol. 92, 368-371.

Chattaraj, P. K. \& Poddar, A. (1999). J. Phys. Chem. A, 103, 86918699.

Cheng, J., Zhu, W., Tang, Y., Xu, Y., Li, Z., Chen, K. \& Jiang, H. (2006). Chem. Phys. Lett. 422, 455-460.

Coletti, C. \& Re, N. J. (2006). J. Phys. Chem. A, 110, 6563-6570.

Cossi, M., Barone, V., Cammi, R. \& Tomasi, J. (1996). Chem. Phys. Lett. 255, 327-335.

Cubero, E., Luque, F. J. \& Orozco, M. (1998). Proc. Natl Acad. Sci. USA, 95, 5976-5980.

Cyvin, S. J., Brunvoll, J. \& Schäfer, L. (1971). J. Chem. Phys. 54, $1517-$ 1522.

Cyvin, S. J., Cyvin, B. N., Brunvoll, J. \& Schäfer, L. (1970). Acta Chem. Scand. 24, 3420-3421.

Damia, G. \& D'Incalci, M. (1995). Clin. Pharmacokinet. 28, 439-448.

Deepa, P., Kolandaivel, P. \& Senthilkumar, K. (2012). Mater. Sci. Eng. $C, \mathbf{3 2}, 423-431$.

D'Incalci, M., Morazzoni, P. \& Pantarotto, C. (1979). Anal. Biochem. 99, 441-449.

Domingo, L. R., Aurell, M. J., Pérez, P. \& Contreras, R. (2002). Tetrahedron, 58, 4417-4423.

Domingo, L. R., Ríos-Gutiérrez, M. \& Pérez, P. (2016). Molecules, 21, 748-770.

Dougherty, D. A. (1996). Science, 271, 163-168.

Ebrahimi, A., Masoodi, H. R., Khorassani, M. H. \& Ghaleno, M. H. (2012). Comput. Theor. Chem. 988, 48-55.

Fraústo da Silva, J. J. R. \& Williams, R. J. P. (2001). The Biological Chemistry of the Elements: the Inorganic Chemistry of Life. New York: Oxford University Press.

Frisch, M. J., et al. (2003). GAUSSIAN03. Revision A.02. Gaussian Inc., Pittsburgh, PA, USA. https://gaussian.com/.

Frontera, A. (2013). Coord. Chem. Rev. 257, 1716-1727. 
Gallivan, J. P. \& Dougherty, D. A. (1999). Proc. Natl Acad. Sci. USA, 96, 9459-9464.

Garau, C., Frontera, A., Quiñonero, D., Ballester, P., Costa, A. \& Deyà, P. M. (2004). J. Phys. Chem. A, 108, 9423-9427.

Gescher, A., D'Incalci, M., Fanelli, R. \& Farina, P. (1980). Life Sci. 26, 147-154.

Ghiassi, H. \& Raissi, H. (2015). J. Sulfur Chem. 36, 48-66.

Ghosh, R., Bharathkar, S. K. \& Kishore, N. (2019). Int. J. Biol. Macromol. 138, 359-369.

Gidwani, B. \& Vyas, A. (2016). Artif. Cells Nanomed. Biotechnol. 44, 571-580.

Glendening, E. D., Reed, A. E., Carpenter, J. E. \& Weinhold, F. (1992). NBO. Version 3.1. http://www.ccl.net/cca/software/MSWIN95-NT/mopac6/nbo.htm.

Glossman-Mitnik, D. (2007). J. Mol. Struct. Theochem, 811, 373-378.

Hassanzadeh, K., Akhtari, K., Esmaeili, S. S., Vaziri, A., Zamani, H., Maghsoodi, M., Noori, Sh., Moradi, A. \& Hamidi, P. (2016). J. Theor. Comput. Chem. 15, 1650056.

Hobza, P. (2008). Phys. Chem. Chem. Phys. 10, 2581-2583.

Hulshoff, A., Neijt, J. P., Smulders, C. F., Van Loenen, A. C. \& Pinedo, H. M. (1980). J. Chromatogr. B Biomed. Sci. Appl. 181, 363-371.

Hunter, C. A., Lawson, K. R., Perkins, J. \& Urch, C. J. (2001). J. Chem. Soc. Perkin Trans. 2, pp. 651-669.

Hunter, C. A. \& Sanders, J. K. M. (1990). J. Am. Chem. Soc. 112 , $5525-5534$.

Jenkins, S. \& Morrison, I. (2000). Chem. Phys. Lett. 317, 97-102.

Keldsen, N., Havsteen, H., Vergote, I., Bertelsen, K. \& Jakobsen, A. (2003). Gynecol. Oncol. 88, 118-122.

Khaleghian, M. \& Azarakhshi, F. (2019). Mol. Phys. 117, 2559-2569.

Khanmohammadi, A., Raissi, H., Mollania, F. \& Hokmabadi, L. (2014). Struct. Chem. 25, 1327-1342.

Kim, K. S., Tarakeshwar, P. \& Lee, J. Y. (2000). Chem. Rev. 100, 41454186.

Klippert, P. M. J., Hulshoff, A., Mingels, M. J. J., Hofman, G. \& Noordhoek, J. (1983). Cancer Res. 43, 3160-3164.

Kosar, B. \& Albayrak, C. (2011). Spectrochim. Acta A Mol. Biomol. Spectrosc. 78, 160-167.

Lemke, T. L. \& Williams, D. A. (2008). In Foye's Principles of Medicinal Chemistry. Philadelphia: Lippincott Williams \& Wilkins.

Ma, J. C. \& Dougherty, D. A. (1997). Chem. Rev. 97, 1303-1324.

Malik, I. A. (2001). Jpn J. Clin. Oncol. 31, 69-73.

Marino, T., Russo, N. \& Toscano, M. (2000). J. Inorg. Biochem. 79, 179-185.

Mecozzi, S., West, A. P. \& Dougherty, D. A. (1996a). J. Am. Chem. Soc. 118, 2307-2308.

Mecozzi, S., West, A. P. \& Dougherty, D. A. (1996b). Proc. Natl Acad. Sci. USA, 93, 10566-10571.

Meot-Ner, M. \& Deakyne, C. A. (1985). J. Am. Chem. Soc. 107, 474479.

Meyer, E. A., Castellano, R. K. \& Diederich, F. (2003). Angew. Chem. Int. Ed. 42, 1210-1250.

Morimoto, M., Green, D., Rahman, A., Goldin, A. \& Schein, P. S. (1980). Cancer Res. 40, 2762-2767.

Müller-Dethlefs, K. \& Hobza, P. (2000). Chem. Rev. 100, 143-168.

Pacios, L. F. (2004). J. Phys. Chem. A, 108, 1177-1188.
Parr, R. G., von Szentpály, L. \& Liu, S. (1999). J. Am. Chem. Soc. 121, 1922-1924.

Pascual-Ahuir, J. L., Silla, E. \& Tuñon, I. (1994). J. Comput. Chem. 15, 1127-1138.

Pearson, R. G. (1987). J. Chem. Educ. 64, 561-567.

Pearson, R. G. (1997). In Chemical Hardness - Applications from Molecules to Solids. Weinheim: VCH-Wiley.

Raissi, H., Khanmohammadi, A. \& Mollania, F. (2013). Bull. Chem. Soc. Jpn, 86, 1261-1271.

Raju, R. K., Bloom, J. W. G., An, Y. \& Wheeler, S. E. (2011). ChemPhysChem, 12, 3116-3130.

Reed, A. E., Curtiss, L. A. \& Weinhold, F. (1988). Chem. Rev. 88, 899926.

Řeha, D., Kabeláč, M., Ryjáček, F., Šponer, J., Šponer, J. E., Elstner, M., Suhai, S. \& Hobza, P. (2002). J. Am. Chem. Soc. 124, 33663376.

Rozas, I., Alkorta, I. \& Elguero, J. (2000). J. Am. Chem. Soc. 122, 11154-11161.

Rulíšek, L. \& Havlas, Z. (2000). J. Am. Chem. Soc. 122, 10428-10439.

Schäfer, L., Southern, J. F. \& Cyvin, S. J. (1971). Spectrochim. Acta A, 27, 1083-1090.

Scherrill, C. D. (2009). In Reviews in Computational Chemistry, ch. 1, Computations of noncovalent $\pi$ interactions. London: John Wiley \& Sons.

Sen, K. D. \& Jorgensen, C. K. (1987). In Electronegativity, Structure and Bonding. New York: Springer.

Shui, X., McFail-Isom, L., Hu, G. G. \& Williams, L. D. (1998). Biochemistry, 37, 8341-8355.

Soteras, I., Orozco, M. \& Luque, F. (2008). Phys. Chem. Chem. Phys. 10, 2616-2624.

Spiegel, K. \& Magistrato, A. (2006). Org. Biomol. Chem. 4, 25072517.

Stanghellini, P. L., Diana, E., Arrais, A., Rossin, A. \& Kettle, S. F. A. (2006). Organometallics, 25, 5024-5030.

Tomasi, J., Cammi, R., Mennucci, B., Cappelli, C. \& Corni, S. (2002). Phys. Chem. Chem. Phys. 4, 5697-5712.

Tsuzuki, S., Yoshida, M., Uchimaru, T. \& Mikami, M. J. (2001). J. Phys. Chem. A, 105, 769-773.

Waters, M. L. (2002). Curr. Opin. Chem. Biol. 6, 736-741.

Wheeler, S. E., McNeil, A. J., Müller, P., Swager, T. M. \& Houk, K. N. (2010). J. Am. Chem. Soc. 132, 3304-3311.

Wintjens, R., Lievin, J., Rooman, M. \& Buisine, E. (2000). J. Mol. Biol. 302, 395-410.

Woodin, R. L. \& Beauchamp, J. L. (1978). J. Am. Chem. Soc. 100, 501-508.

Wouters, J. (1998). Protein Sci. 7, 2472-2475.

Zaboli, M. \& Raissi, H. (2015). J. Theor. Comput. Chem. 14, 1550044.

Zhao, Y., Schultz, N. E. \& Truhlar, D. G. (2005). J. Chem. Phys. 123, 161103.

Zhao, Y., Schultz, N. E. \& Truhlar, D. G. (2006). J. Chem. Theory Comput. 2, 364-382.

Zhao, Y. \& Truhlar, D. G. (2006). J. Chem. Phys. 125, 194101.

Zhao, Y. \& Truhlar, D. G. (2007). J. Chem. Theory Comput. 3, 289300.

Zhao, Y. \& Truhlar, D. G. (2008). Theor. Chem. Acc. 120, 215-241. 